\title{
Applications of Computer-based Neuropsychological Assessment
}

\begin{abstract}
Objectives: To present current applications of computer-based neuropsychological assessment, including the assessment of sports-related concussion, symptom validity testing, and the remote administration of tests through the Internet. Problem areas: If computer-based assessment benefits are to become popularized, a few issues will need to be addressed: the development of psychometric data based on comparisons with long-standing empirically sound test measures; additional validation of measures by parties not involved in their commercial development; increased focus on ecological validity; exploration of the usefulness of remote data storage and automated posting to databases; and improved documentation of specific computer hardware and software used in experimental methods. Conclusions: Beyond ease of administration and data collection, computer-based assessment offers benefits over paper-and-pencil measures in the form of millisecond timing accuracy, reliable and randomized presentation of stimuli over multiple trials and repeat administrations, and unobtrusive measurement of cognitive skills and response times during all aspects of the assessment process. Key words: assessment, computer, concussion, evaluation, Internet, neuropsychology, symptom validity
\end{abstract}

\author{
Philip Schatz, PhD \\ Assistant Professor of Psychology \\ Saint Joseph's University \\ Philadelphia, Pennsylvania \\ Jeffrey Browndyke, PhD \\ Clinical Neuropsychology Fellow \\ Department of Psychiatry and \\ Human Behavior \\ Brown Medical School \\ Providence, Rhode Island
}

\begin{abstract}
A CADEMICIANS AND researchers have

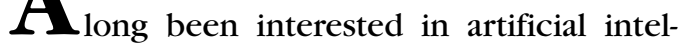
ligence, computer assisted and automated interviewing, and computerized assessment, dating back to the early 1950s. The resultant issues of reliability and validity, ${ }^{1}$ advantages and disadvantages, ${ }^{2}$ client reactions, ${ }^{3}$ storage and confidentiality of records,${ }^{4}$ and ethics ${ }^{5}$ have been widely studied and well documented. Since the introduction of the personal computer in the early 1980s, the percentage of US households with a computer has risen dramatically, from only $8.2 \%$ in 1984 to $42 \%$ in 1998 and $52 \%$ in $2000 .^{6}$

Despite this increase in home computer use, psychologists have been relatively slow to embrace applied computer technologies in their work. Although $90 \%$ of psychologists surveyed listed telephone-based consultative services as "common behavior," there were no computer-related technologies that emerged as integral to psychological contact
\end{abstract}

Address correspondence and reprint requests to: Pbilip Schatz, PbD, Saint Joseph's University, Department of Psychology, 5600 City Avenue, 222 Post Hall, Philadelphia, PA 19131. E-mail: pschatz@sjv.edu.

J Head Trauma Rebabil 2002;17(5):395-410

(c) 2002 Lippincott Williams \& Wilkins, Inc 
or service. ${ }^{4}$ Ironically, as managed care operations continue to stress relatively rigid reimbursement schedules for clinical contact time, the automation and standardization of traditional face-to-face mental health services may prove to be a partial solution. Practical uses of computer technology have been recognized as contributing to more cost-effective clinical practices, ${ }^{7}$ and mental health professionals are beginning to adopt computers as a means of addressing the cost-efficiency demands generated by managed care. ${ }^{8}$ Research has shown that psychologists do use computers in their practice, but only a fraction reported using a computer for anything beyond routine word processing. ${ }^{9}$ Additional surveys have revealed the use of computers in clinical neuropsychology practices for the purposes of test administration and scoring, research activities, billing, and record keeping, although not at a level commensurate with technological integration in other professions and fields. ${ }^{10}$ This review will focus on current trends in the application and use of computerbased neuropsychological assessment.

\section{HISTORICAL PERSPECTIVE ON COMPUTER-BASED ASSESSMENT}

Many traditional paper-and-pencil neuropsychological tests have been computerized; the Peabody Picture Vocabulary Test ${ }^{11}$ and the Raven's Coloured Progressive Matrices ${ }^{12}$ are two salient examples. Perhaps the most widely used measure to be computerized was the Wechsler Adult Intelligence Scale (WAIS). Currently, and for the past few decades, the WAIS has been the most widely used psychological and neuropsychological test in its various evolutionary forms (WAIS-R, WAISIII). ${ }^{13-15}$ The original version of the WAIS was automated in $1969^{16}$ using what would be best described today as a primitive and crude means of stimulus presentation and response recording. However, this early form of automated assessment yielded excellent test-retest reliability, concurrent validity with face-toface administration, ${ }^{16,17}$ and lower administration costs. ${ }^{18}$ The WAIS was automated again in $1980,{ }^{19}$ and the paper-and-pencil versions were revised in 1980 and 1999. Despite numerous attempts at automation, in its current form, the WAIS-III remains essentially a penciland-paper test. Yet, the usefulness of computerized scoring for the measure has never been more popular and assists the clinician by reducing paperwork time.

The Halstead-Reitan Neuropsychological Test Battery ${ }^{20}$ was originally developed to predict the presence and localization of brain damage. Although considerable efforts have focused on computerizing the interpretation of Category Test results, ${ }^{21}$ however, the results of these efforts have neither adequately nor universally demonstrated the superiority of actuarial decision making over clinical judgment. $^{22}$ The Category Test is the lone subtest of the Halstead Reitan Battery to receive considerable research attention with respect to computerization. The Category Test was first computerized in $1975,{ }^{23}$ providing changing stimuli and response recording, including response latency measurement. Although this computerized version was not found to be a valid substitute for the standard Category Test, another computerized version of the Test surfaced in the late 1980s. ${ }^{24}$ Advanced microcomputer technology allowed for full automation of the Category Test with the exception of verbal instructions and prompts necessary for task completion. This computerized version of the Category Test demonstrated an acceptable level of equivalence with the original version of the Category Test. ${ }^{25}$ Two additional computerized Category Test versions have been developed, ${ }^{26,27}$ both of which were found to be essentially equivalent to the original. ${ }^{28}$ The Wisconsin Card Sorting Test ${ }^{29}$ has also been identified as one of the most widely used neuropsychological tests, ${ }^{30}$ and there are numerous commercial computerized versions of the $\mathrm{WCST}^{31}$ 
currently in use. ${ }^{32}$ Despite the fact that most, if not all, computerized versions of the WCST have not demonstrated psychometric equivalence with the standard manual versions, ${ }^{33,34}$ the literature shows extensive use of the computerized version. ${ }^{35}$

Numerous traditional neuropsychological measures, beyond those presented here, have been translated into a computerized format. However, the main focus of this article is on practical applications of computer-based assessment for clinicians and rehabilitation specialists; as such, we have presented only a small portion of the neuropsychological measures that have been automated or computerized. For more comprehensive historical perspectives of computer-based testing and computerized neuropsychological assessment batteries, refer to reviews by Bartram and Bayliss ${ }^{18}$ or Kane and Kay. ${ }^{36}$

\section{BENEFITS OF COMPUTER-BASED ASSESSMENT}

To address the limitations and benefits of computerized assessment, the American Psychological Association (APA) in 1987 established Guidelines for Computer-based Tests and Interpretations. ${ }^{37}$ The APA recognized a number of potential benefits that can be derived from the proper use of a computer in the delivery of clinical services (Table 1).

In general, researchers have been able to demonstrate psychometric equivalence between traditional and computerized versions of tests. ${ }^{16,38}$ Computer-based assessment has inherent features that are absent in traditional forms, such as timing of response latencies, automated analysis of response patterns, transfer of results to a database for further analysis, or the ease with which normative data can be collected or compared with existing normative databases. ${ }^{2}$ In addition, computer-based assessment measures are better able to provide precise control over the presentation of test stimuli, thereby potentially increasing test reliability. In a computerized test, the software controls visual and auditory stimulus characteristics, and other features such as color, animation, and sound can be easily incorporated into all aspects of the assessment process, including the instructions. ${ }^{2}$ As such, programs can adaptively control the order, number, presentation rate, and complexity of items, as well as other aspects of auditory and visual stimuli, many of

Table 1. Potential benefits of computer-based clinical service delivery

- Computer software can capture and engage the interest of the client.

- Properly constructed and presented software programs can help minimize a client's frustration and loss of dignity when working on tasks once accomplished with ease.

- The context of learning to use the computer can provide the client with an experience of mastery and a sense of control.

- Automated data collection and storage can free the clinician to focus more on treatment.

- The computer can measure multiple dimensions of performance (latency, strength, and locus of response) at levels not possible for the human observer (e.g., milliseconds, grams, and millimeters).

- The computer is efficient at performing tasks that would otherwise require extensive setup and/or preparation time (e.g., rapid change of font size for reading tasks, rapid modification of graphic materials).

Adapted from American Psychological Association. Guidelines for Computer-based Tests and Interpretations Washington, DC: American Psychological Association, 1986. 
which cannot be achieved with conventional testing. ${ }^{39,40}$

From a financial perspective, computerbased assessment can reduce disposable materials, saving costs in supplies and storage. Researchers have demonstrated that computer-based cognitive tests offered a $60 \%$ savings in time over traditional administration with an adult psychiatric population. ${ }^{3}$ And, if handled properly and judiciously, computerized storage mediums afford increased security of test data and patient records. ${ }^{41}$ For the practitioner, the option to use an established, reliable, and valid measure with standardized instructions and means of presentation may be desirable or advantageous, especially when working with a specific patient population or suspected diagnosis for which the test was developed. As well, practical applications include portability of standardized measures to on-site assessments at a client's location.

\section{OBSTACLES AND LIMITATIONS}

Among the central criticisms of computerbased assessment noted by the $\mathrm{APA}^{37}$ were some test developers' failure to meet established testing standards. Others have pointed to poorly designed human-computer interfaces and a reduction in the amount of face-to-face interaction between the clinician and examinee. ${ }^{42}$ Furthermore, it has been suggested that the mode of administration is so dramatically different an experience for the examinee that computer-based assessment and traditional administration can never be equivalent. ${ }^{43}$ To this end, factors extraneous to the paper-and-pencil assessment are introduced during computer-based assessment, and these factors must be identified and evaluated with respect to their potentially disruptive effects. ${ }^{44}$ Obstacles to the use of computer-based assessment have also been attributed to the test user or clinician. Although most clinicians have become quite familiar with word processing and financial software packages, there are many who have at least a mild degree of computer phobia, which taints their perception of the usefulness of computer-based assessment. ${ }^{45}$ These personal fears may fuel the misperception that most patients are largely reticent to interact with computers, a perception that does not seem to be substantiated by the literature. ${ }^{36,39,46}$ In addition, computer-based assessment techniques may not address the dynamic needs of clients with "challenging" behavioral disorders or symptoms. Such neurobehavioral presentations may require the clinician to alter the order, schedule, or pace of the assessment, and such alterations may not be possible with computer-based techniques.

Some practical and technical limitations of computer-based assessment have been voiced as contributing factors to the general reticence within clinical neuropsychology to adopt computerization on a large scale. ${ }^{10,36}$ An example of one of the more serious technical deficiencies has been the use of testing software with inaccurate timing procedures. ${ }^{47}$ Essentially, synchronization between the computer's processor and the monitor occurs with some amount of delay, or error, in timing. Although it was initially difficult to standardize or control this delay with a degree of consistency, researchers have since developed software solutions that provide near-millisecond accuracy. ${ }^{48}$ Free software programs, such as PsyScope ${ }^{49}$ and commercial software programs, such as PowerLab ${ }^{50}$ (Macintosh platform only) and MediaLab ${ }^{51}$ (Windows platform only), are readily available. These programs provide the ability to develop customized computer-based experimental protocols, incorporating multimodal visual, auditory, and multimedia stimuli. For the clinician wishing to obtain a gross measure of reaction time or response onset latency, millisecond accuracy may not 
be the most important requirement when considering computer-based assessment measures. However, there have been recent trends toward collaborative research efforts between cognitive neuroscientists, neuropsychologists, and radiological medicine, especially in the study and use of functional magnetic resonance imaging (fMRI) to observe brain-behavior relationships. Computers are often used to coordinate the "chain of events" in which stimuli are presented for fMRI data acquisition, and this coordination requires synchronization within very specific time intervals. In such cases, ${ }^{52,53}$ accurate timing to the millisecond is not only crucial, but uncontrolled error margins between stimulus onset and actual stimulus display may result in "noise" rather than useful data.

Methodologically, computerized assessment techniques are not without their flaws. The automated nature of many computerized measures does not allow the examiner to interrupt or stop the assessment, and this rigidity may ultimately decrease the examiner's ability to "test the limits" or be more flexible with their evaluation. By nature, computerized measures present stimuli either through visual or auditory modalities. This existing paradigm does not allow for the collection of spontaneous verbal responses, thus eliminating the ability to test verbal functioning with the use of computerized measures. In addition, computerized measures generally collect responses through either mouse clicks or keyboard responses, which may be severely limiting to individuals with physical or motor control deficits. As well, whereas computerization of measures may translate to increased portability, bedside evaluations with even a laptop computer may be awkward or challenging. To compensate for these limitations, developers of computerized tests should to be aware of the unique and individual differences inherent in different target populations and incorporate timing controls and alternate stimulus delivery modes that can be customized by the examiner and incorporate voice recognition for verbal responses.

\section{CURRENT TRENDS IN COMPUTER-BASED NEUROPSYCHOLOGICAL ASSESSMENT}

\section{Sports-related concussion}

An important emergent property of computerized assessment may be its portability to multiple sites and the ability to assess multiple individuals simultaneously with highly sensitive measures. One area that seems to have embraced this technology is the assessment of sports-related concussion, which has received considerable attention over the past two decades. Neuropsychologists and athletic trainers have traditionally provided sideline screening measures and more comprehensive baseline and postconcussion evaluations to athletes using a variety of qualitative and quantitative measures.

Traditionally, athletes have been assessed face-to-face with comprehensive neuropsychological test batteries, which have been used to understand and document the effects of cerebral concussion in professional football ${ }^{54}$ and professional ice hockey players, ${ }^{55}$ as well as in college, ${ }^{56-58}$ high school, ${ }^{59}$ and grade school athletes. ${ }^{60}$ These traditional neuropsychological assessments identified single mild head injuries in healthy college-aged athletes as causing a decrease in neurocognitive performance, with a relatively rapid recovery curve ranging from 5 to 10 days $^{56}$ up to 1 month after concussion. ${ }^{61}$ Cerebral concussion in individuals with a history of previous concussion ${ }^{59}$ or learning disability $^{62}$ were found to have more enduring cognitive effects. In all of the studies noted previously, cerebral concussions were observed to have at least subtle effects on attention and concentration. To this end, 
computer programs with accurate timing may be best suited to identify deficits and track recovery progress, especially when postconcussive symptoms include delayed onset of responses and increased decisionmaking times (i.e., reduced information processing speed).

Baseline assessment of athletes has been recognized as a paramount requirement in the evaluation of athletes before sustaining a concussion. Evaluation of an entire team or "season" (such as all teams reporting for physicals before the fall semester) with traditional measures might take several days or weeks, depending on the number of staff available. With computer-based assessment, large groups of individuals can be assessed in a brief period of time with decreased burden on time, labor, and finances. To this end, isolated studies have focused on replicating hallmark studies ${ }^{56}$ using computer-based versions of their test protocol. ${ }^{63}$ However, the thrust of the recent research in this area has been on the development and validation of comprehensive neuropsychological test batteries for the assessment and tracking of cognitive deficits related to sports-related concussion. Three major batteries have emerged from these efforts: CogSport, HeadMinders, and Impact.

CogSport $^{64}$ is a stand-alone software product that measures reaction time, simple and complex attention, working memory, shortterm memory and new learning, incidental memory, adaptive problem solving, continuous performance, and spatial abilities. It is designed to evaluate changes in cognitive function. The battery has recently been validated on approximately 300 professional Australian football players and hundreds of healthy controls across a wide range of ages, ${ }^{65}$ showing good test-retest coefficients and external validation with the Trail Making and Digit Symbol Substitution Tests. ${ }^{66}$ CogSport is available for both Windows and Macintosh operating systems, administration takes approximately 15 to 20 minutes, and results are submitted to CogState for scoring and analysis. Alternatively, CogState Ltd. offers user services in the form of customized reports, custom results ready for import into popular statistical packages (Excel, SPSS, SAS), assistance in interpretation of results for publication or presentation, storage and retrieval of data and results, and mirroring of stored data for data protection.

HeadMinder Inc. offers online neurocognitive and neurobehavioral assessment tools in the form of the Concussion Resolution Index (CRI) and Sideline Assistant (SA). ${ }^{67}$ The CRI subtests are administered on-line by means of Java "applets" through an Internet browser and are thus computer platform independent. The CRI subtests measure reaction time and speed decision making and show strong concurrent validation with the Symbol Digit Modalities Test, WAIS-III Digit Symbol and Symbol Search, Grooved Pegboard, and Trail Making Tests. ${ }^{68}$ Test measures are scored online, and results are accessible only to the test administrator who is responsible for interpreting and discussing test results with that athlete. The CRI has been found to be sensitive in identifying postconcussive symptoms, while remaining resistant to retest effects. ${ }^{68,69}$ The Sideline Assistant is a personal digital assistant (PDA)-based software application containing a roster of all athletes and pertinent medical and contact information, as well as an electronic version of the Standardized Assessment of Concussion. ${ }^{70}$

ImPACT (Immediate Post Concussion Assessment \& Cognitive Testing) test system ${ }^{71}$ is a microcomputer-based neuropsychological test battery that measures attention, memory, processing speed, and reaction time to $1 / 100$ th of a second. The Windows-based program also consists of a self-report symptom questionnaire and a concussion history form. ImPACT is currently used by professional football, hockey, and basketball teams, as well as numerous colleges and high schools. Initial psychometric research on the ImPACT System 
reveals strong reliability data ${ }^{72}$ and validation research are in progress.

\section{Symptom validity testing}

Neuropsychologists and other rehabilitation specialists may be asked to judge the veracity or extent of a client's symptoms or even to identify individuals who may be exaggerating or faking symptoms of neurocognitive impairment. In the process of making these judgments, the clinician attempts to document, with the assistance of objective assessment procedures, evidence of true neurobehavioral and/or neuropsychological dysfunction. ${ }^{73}$ Computer-based assessment provides the ability to objectively and unobtrusively record response reaction times, because many individuals attempting to fake or exaggerate cognitive impairment fail to realize these measurement variables are being recorded. These individuals may even know to perform at a certain level to avoid suspicion of symptom exaggeration. However, even if they are aware that reaction times are being recorded, it is difficult for these individuals to calculate or manipulate response reaction time with any degree of sophistication. ${ }^{74}$ In fact, individuals attempting to fake or exaggerate deficits have been found to perform worse than individuals with actual brain injuries.

Numerous computer-based measures have been developed, many of which have been used as for the purpose of identifying individuals who may be faking or exaggerating cognitive deficits. Symptom Validity Testing (SVT) is a term that was first described by Pankratz ${ }^{75}$ and refers to the use of forcedchoice measures designed to detect feigned test performance. Often, such performance is so poor that it is below the level of probability, even for impaired populations. ${ }^{76}$ Hiscock and Hiscock ${ }^{77}$ refined this technique, and their work served as a foundation for many of the SVT procedures that are currently in use today. Because comprehensive reviews of SVT are available in the literature, ${ }^{76,78}$ the following measures have been selected to demonstrate the usefulness and application of SVT.

The Victoria Symptom Validity Test (VSVT), ${ }^{79}$ Computerized Forced-Choice Test (CFCT), ${ }^{74}$ Computerized Assessment of Response Bias (CARB), ${ }^{80}$ and Word Memory Test (WMT) ${ }^{81}$ are commonly used computerized forced-choice SVTs. The VSVT is a Windows-based computerized task that has been used to classify malingerers of memory deficits, questionable malingerers, or valid test-takers with a high degree of sensitivity, ${ }^{82}$ and cut-off scores have been developed for this purpose. ${ }^{83}$ Computerized assessments using the VSVT yielded unique intraindividual variability data that helped differentiate among those feigning symptoms related to head trauma and those performing their best, and the response inconsistency across testing sessions is believed to be a clinically useful measure for the detection of malingering. ${ }^{84}$ The CFCT is a Macintosh-based computerized task that has been shown to be psychometrically comparable with the Hiscock and Hiscock $^{77}$ pencil-and-paper-based measure. A shortened form of the CFCT is available, which yields significant differences between groups of individuals feigning malingering and performing their best, while maintaining high levels of response consistency; in addition, response reaction times for individuals feigning malingering are significantly higher. $^{74}$ The CARB is a self-administered test designed according to the Hiscock and Hiscock paradigm and has demonstrated usefulness for detecting incomplete effort, symptom exaggeration, response bias, and feigning and malingering of cognitive deficits, especially when used in combination with other neuropsychological test measures. ${ }^{85}$ The WMT can be given orally or by computer and has an inherent gradient of difficulty, which makes feigning impairment difficult. The WMT has been shown to discriminate 
between levels of brain injury severity ${ }^{86}$ and is used along with the CARB to identify individuals feigning impairment. ${ }^{87}$

Noticeably absent are computerized versions of the traditionally used tests of malingering, such as Rey's 15-item and Dotcounting tests. Recent research ${ }^{88}$ focused on computerizing these measures using PowerLab, ${ }^{50}$ along with developing a novel task, the "Phrases" task in which participants are required to fill in the blank of a common phrase (i.e., birthday to you), then choose the correct word, and subsequently the correct picture, from the three choices provided. In this study, all computerized tests discriminated between groups of individuals feigning cognitive deficits and those performing their best. Moreover, response reaction times for individuals feigning cognitive deficits were significantly slower for those tasks in which the incorrect responses were obvious (Dot-counting test-grouped), and significantly faster when the correct response was not readily available (Figure 1 ). Simply put, individuals feigning cognitive deficits take significantly longer to respond to obvious and simple items, because they must not only generate the correct answer but also identify and generate a suitable alternative. In those cases in which the correct answer is not obvious, individuals feigning cognitive deficits simply opt for a suitable answer, seemingly unaware of their response times. In addition, all participants showed a learning curve for response times to identical instruction screens presented on four occasions, and such learning ability was clearly out of register with the magnitude of cognitive symptoms portrayed by those individuals feigning cognitive deficits (Figure 2). These results support the notion that computer-based tests can unobtrusively obtain qualitative and quantitative data not available through paper-based measures.

\section{Remote neuropsychological assessment}

The recent growth of the telecommunication industry and Internet-based technologies offers opportunities for computer-based neuropsychological assessment to expand

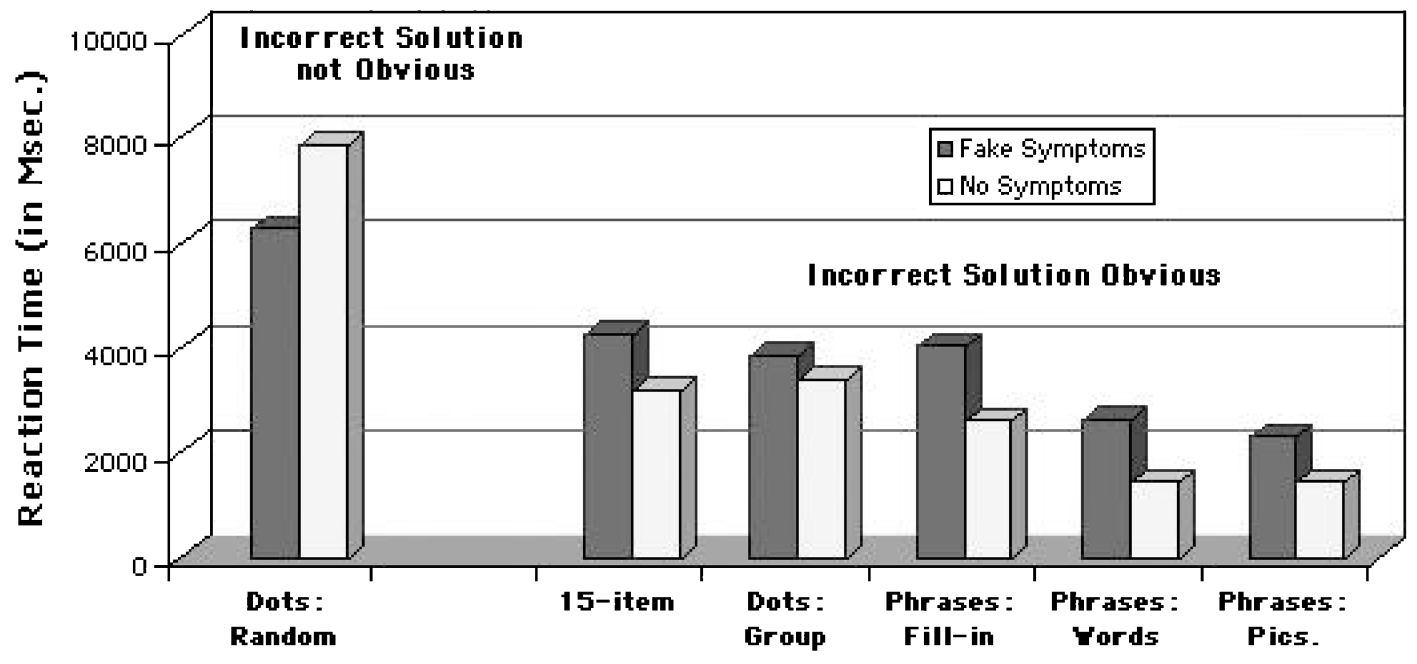

Fig 1. Reaction time by response requirement effects. 


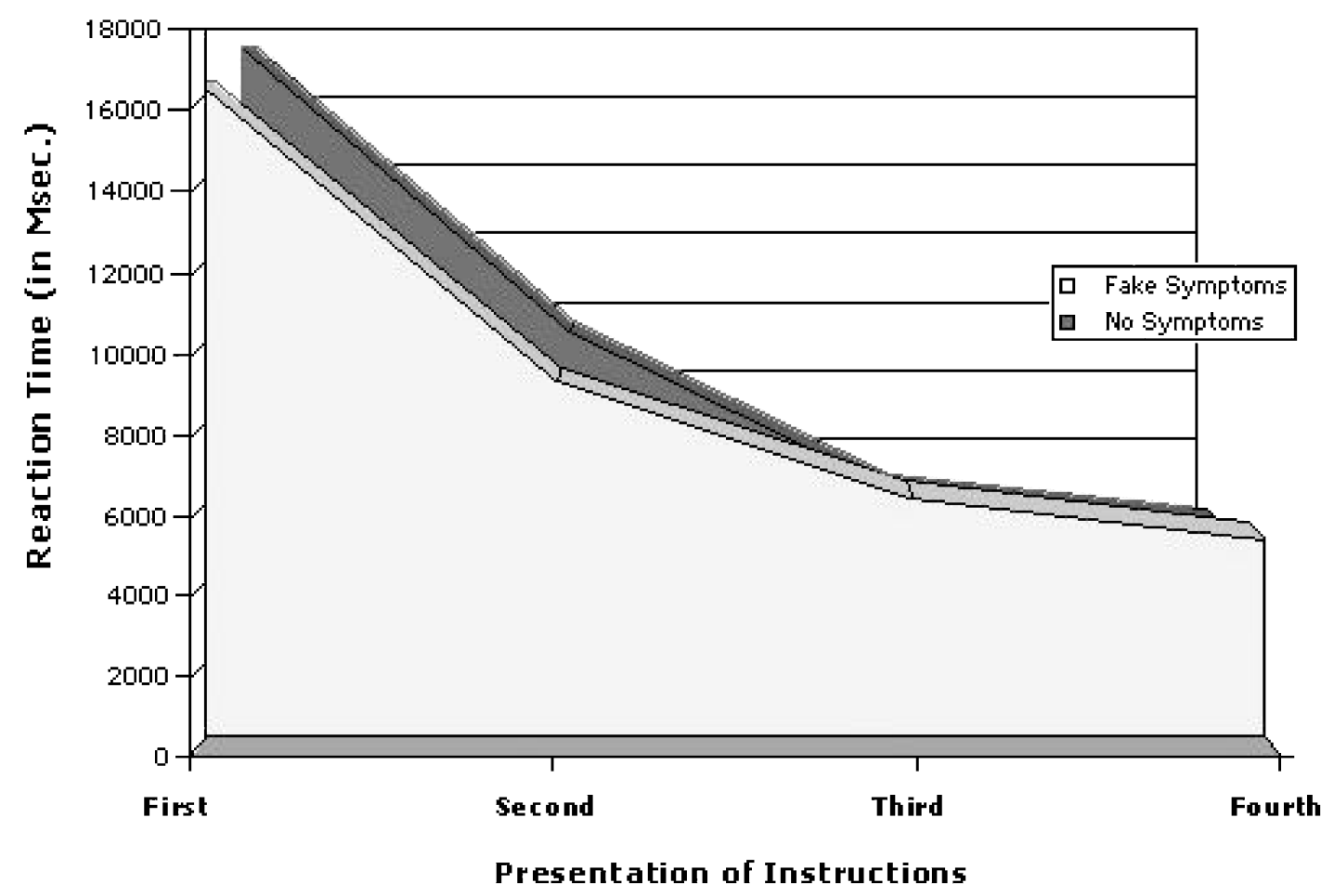

Fig 2. Reaction times for instruction screens.

beyond traditional clinic or laboratory borders. The term, "remote neuropsychological assessment (RNA)," has been proposed to denote the general use of telecommunication and Internet-based technologies in neuropsychological assessment and practice. ${ }^{27}$

Researchers have reported the development and use of remote cognitive assessment measures ${ }^{89-95}$; however, practically all of these studies have been limited to the use of conventional telephony or televideo technologies. It should be noted, however, that as telecommunication systems expand their bandwidth capacity, thereby increasing the speed and amount of information that can be carried simultaneously by data transmission lines, telephony and televideo may eventually become standard Internet-based technologies. ${ }^{96}$ For the purpose of this review, discussion will be limited to those efforts that have used computerized, Internetbased technology to assess neurocognitive function. More comprehensive reviews of conventional telephony assessment, ${ }^{97}$ conventional televideo assessment, ${ }^{98}$ and Internet use by clinicians ${ }^{99}$ are available in the literature.

Save for a few notable exceptions, ${ }^{27,68,69,100}$ Internet-based computer technology has been largely underused for the remote administration of neuropsychological measures and assessment. Early research efforts ${ }^{101,102}$ were helpful in establishing the viability of Internet technology for use by neuropsychology. These studies, although limited to the administration and collection of questionnaire data 
by way of the Internet, reported the effective use of this technology for the collection of data related to mild traumatic brain injury and postconcussion symptom complaints. Recent efforts by Browndyke ${ }^{27}$ and Erlanger and colleagues ${ }^{68,69}$ have moved remote assessment in neuropsychology beyond simple Web-based questionnaire collection. The logical progression, exemplified by these more recent studies, involves task performance on assessment measures specifically developed for RNA, as well as the translation of traditional paper-and-pencil measures to remote format. To be certain, the science and clinical application of RNA is still in its infancy.

Regardless of the speed of RNA development, the need for empirical, procedural, ethical, and professional practice guidelines for RNA is quite clear. To date, most serious RNA development efforts have been conducted in relative isolation with varying standards for data transmission, platform dependence, normative comparison, and clinical application. In addition, there have been more conspicuous and relaxed efforts in Internet-based cognitive assessment, most of which traverse the fine line of ethical and professional propriety. For example, currently there are efforts underway by various companies to mass market computerized cognitive assessment, and in some cases, going so far as to develop and use repeatable Internet-based cognitive measures as "brain improvement" programs. ${ }^{103}$ Although these companies state that their programs are not to replace or exclude neuropsychological assessment by a licensed professional, this caveat is often lost on the public and generates the impression that cognitive assessment is a game. Some additional concerns central to the viability and professional acceptance of RNA revolve around issues of data security, ${ }^{104}$ the impact of affective variables on test performance, ${ }^{100,105}$ generational effects and apparatus familiarity, ${ }^{106,107}$ and human-computer factors affecting task design and development. ${ }^{108}$ These factors, combined with the need for neuropsychology to maintain a professional and guiding presence, argue for the formation of practice directorates similar to previous efforts undertaken to address issues related to computer-based neuropsychological assessment measures ${ }^{109}$ or rehabilitation software. ${ }^{110}$

RNA holds considerable promise for reaching individuals who would otherwise not seek a laboratory-based neuropsychological evaluation, may be homebound, or live in inaccessible regions of the world. The potential benefits of RNA have already been demonstrated in the adaptation of long-standing paper-andpencil neuropsychological assessment measures for remote use ${ }^{27}$; in the repeat cognitive screening of certain patient populations (see Erlanger et al, in this issue); and in sportsrelated cognitive evaluation and return-toplay decision making. ${ }^{69}$ However, before the widespread implementation of RNA, broader measures of cognitive functioning will need to be developed. To this end, significantly more patient samples and comparison groups will have to be examined, normative data will need to be generated (specific to RNA measures), and most importantly, guidelines must be developed to ensure ethical and professional compliance. Establishing a more solid empirical basis for RNA will be vital to the longevity and effectiveness of distance technology in clinical neuropsychological practice and will guarantee the attention of those in search of a more efficacious means for neuropsychological assessment while keeping scientific rigor to a maximum.

\section{SUMMARY AND FUTURE DIRECTIONS}

Computer-based $\begin{array}{r}\text { neuropsychological } \\ \text { assessment has evolved from several } \\ \text { psychology-related disciplines, the most }\end{array}$


notable of which have been human factors, cognitive psychology, and practitioners of clinical psychology and neuropsychology. Traditional neuropsychological tests and measures have been replicated with general equivalence to their paper-and-pencil predecessors. ${ }^{16,38}$ Unique, goal-specific test batteries have been developed for the purposes of synchronizing stimuli with functional imaging technologies, ${ }^{52,53}$ for more precise and expedient assessment of sports-related concussion, ${ }^{64,67,71}$ and for increased sophistication of symptom validity testing. ${ }^{74,79,83,85}$

Recent trends and national statistics suggest that computer and Internet technologies have moved from "emergent" status to "current" acceptance. Despite major technological advances, such as fMRI, terra-byte storage capacities, and ever-climbing microprocessor speed, nearly all aspects of clinical service delivery remain paper-based. Regardless of the self-reported reticence of professionals with respect to computer technology, clinicians base their practices on traditional models of diagnosing impairment and making suggestions to maximize functional strengths and compensate for weaknesses. Within this context, the use of computer technology often amounts to nothing more than report writing (word processing), communication with peers (e-mail), and/or comparative research (Internet-based literature searches).

Currently, there is a general lack of methodological detail in the literature with respect to computer-based assessment measures and interventions. Although it was once commonplace to find detailed apparatus descriptions, such as product numbers or specific impedance ratios, modern methodological descriptions are apt to be limited to naming the software product in combination with a publication reference, with no specific mention of the computer, operating system, or other technological data. This lack of detail, although seemingly innocuous, hampers future research and replication studies necessary for the firm confidence that must be generated if computer-based assessment is to become widely accepted.

Computerization of paper-and-pencil measures often results in replication for specific purposes, such as ease of administration, group administration, data collection, or research. In this vein, computerized versions of the WAIS were strictly used in research, and versions of the Category Test, Wisconsin Card Sorting Test, and Stroop Test have not achieved widespread used by clinicians. ${ }^{10}$ Despite the considerable experimental control offered by computerization, traditional measures, such as the Finger Tapping test, continue to rely on human visualization of a stopwatch and termination of trials by voice command and, thus, will always be administered with inherent timing error. Computerization of this measure would ensure standardization of administration and scoring.

Current applications of computer-based neuropsychological assessment, such as assessment of sports-related concussion and symptom validity testing, do take advantage of the emergent properties offered by technology. Automatic randomization of trials and millisecond-accurate timing allow for reliable and repeat administration. Computerbased assessment also offers unobtrusive measurement of response times, especially to seemingly nonexperimental stimuli, not possible with paper-based measures. Remote neuropsychological assessment offers similar advantages, while providing a unique alternative to traditional face-to-face administration.

One obstacle to the development and implementation of applied technological "end products" within neuropsychology and rehabilitation may be the lack of commercial technologies or applications for the development of practical measures or interventions. Instead, researchers and clinicians have more often relied on self-developed or 
relatively esoteric products, idiosyncratic to a specific computer platform or institution. Although computerized assessment has demonstrated usefulness beyond mere ease of administration, the issue of ecological validity of computer-based measures is less emphasized. Few neuropsychological measures offer the diagnostic ecological validity of accompanying a client on a trip to the supermarket, navigating the community, or performing profession-specific tasks. However, few clinicians or facilities have the time and resources to fund or develop such interventions or assessment. A recent example of computerization aiding the development of ecologically valid methods is the Schultheis' Neurocognitive Driving Test. ${ }^{111}$ With the emergence of three-dimensional virtual reality technology, the assessment of driving ability ${ }^{112}$ is a clear example of an emergent technology (see Schultheis' article in this issue.)

Computer-based assessment will surely benefit from a documented standard beyond those recommendations offered by the APA. ${ }^{37,109}$ Although the ethical issues raised by data "sharing" over the Internet remain to be worked out, tests that output results directly to databases for self-standardization, comparative research, and/or clinical comparison are fast approaching. However, development, implementation, promotion, and standardization of technological interventions and measures is simply too large for any one clinical practice or service-oriented department. In the absence of such standardization, national organizations and professional societies may need to take responsibility for technological applications within their discipline. As a model, the National Academy of Neuropsychology has been at the forefront of implementing technology to benefit its membership and community. However, provisions of Internet-based continuing education courses and dissemination/gathering of practice-related information by means of a Web site are only first steps toward the profession embracing emerging technologies. Ongoing surveys, further refinement and standardization of computer-based testing and measurement issues, and continuing public and professional education will be needed to support such developments.

Future research on computer-based assessment would benefit from the following:

1. Researchers and clinicians should include specific documentation of computer hardware and software used in the development and administration of computer-based measures.

2. Psychometric data from computer-based measures should be established in comparison to long-standing and psychometrically sound test measures.

3. Developers of computerized tests should compensate for the unique and individual differences inherent in different target populations by incorporating timing controls and alternate stimulus delivery modes that can be customized by the examiner and by incorporating voice recognition for verbal responses.

4. Research is needed to fully establish the psychometric properties of new computer-based measures. Such research, especially by additional parties beyond those involved in their commercial development, would serve to promote the usefulness and ecological validity of these measures.

5. Efforts should focus not only on the development of computer-based measures but also on the development of "measure development" software (or the equivalent of a word processor for developing experiments).

6. Remote assessment by way of the Internet should be further explored, as well as remote forms of automated data storage and collaborative data sharing. 
1. Epstein J, Klinkenberg WD. From Eliza to Internet: a brief history of computerized assessment. Comput Hum Behav. 2001;17:295-314.

2. Wilson SL, McMillan TM. Microcomputers in psychometric and neuropsychological assessment. In: A. Ager, ed. Microcomputers and Clinical Psychology: Issues, Applications and Future Developments. Chichester, England: John Wiley and Sons, Ltd.; 1991:79-94.

3. French CC, Beaumont JG. The reaction of psychiatric patients to computerized assessment. Br JClin Psychol. 1987;26:267-277.

4. McMinn MR, Trey Buchanan T, Ellens BM, Ryan MK. Technology, professional practice, and ethics: survey findings and implications. Prof Psychol-Res Pr. 1999;30:165-172.

5. Walker NW, Cobb-Myrick C. Ethical considerations in the use of computers in psychological testing and assessment. J School Psychol. 1985;23:5157.

6. Newburger EC. Current Population Reports: Home Computers and Internet Use in the United States, August 2000. Washington, DC: U.S. Department of Commerce, US Census Bureau; 2001.

7. Sturges JW. Practical use of technology in professional practice. Prof Psychol-Res Pr. 1998;29:183188.

8. Jerome LW, DeLeon PH, James LC, Folen R, Earles J, Gedney JJ. The coming age of telecommunications in psychological research and practice. Am Psychol. 2000;55:407-421.

9. Rosen LD, Weil MM. Psychologists and technology: a look at the future. Prof Psychol-Res Pr. 1997;27:635-638.

10. Schatz P, Browndyke JN. Trends in computer usage and means of obtaining $\mathrm{CE}$ credits among professional psychologists. Arch Clin Neuropsychol. 1999; $14: 159$

11. Space LG. A console for the interactive on-line administration of psychological tests. Behav Res Meth Instr. 1975;7:191-193.

12. Waterfall RC. Automating standard intelligence tests. J Autovisual Media Med. 1979;2:21-24.

13. Hartlage LC, Telzrow CF. The practice of clinical neuropsychology in the US. Arch Clin Neuropsychol. 1980;2:200-202.

14. Guilmette TJ, Faust D, Hart K, Arkes HR. A national survey of psychologists who offer neuropsychological services. Arch Clin Neuropsychol. 1990;5:373392.

15. Lees-Haley PR, Smith HH, Williams CW, Dunn JT.
Forensic neuropsychological test usage: an empirical survey. Arch Clin Neuropsychol. 1996;11:4551.

16. Elwood DL, Griffin R. Individual intelligence testing without the examiner. J Consult Clin Psychol. 1972;38:9-14.

17. Coons WH, Peacock EP. Inter-examiner reliability of the Wechsler Adult Intelligence Scale with mental hospital patients. Ontario Psychol Assoc $Q$. 1956;12:33-37.

18. Bartram D, Bayliss R. Automated testing: past, present and future. J Occup Psychol. 1984;57:221237.

19. Vincent KR. Semi-automated full battery. J Clin Psychol. 1980;36:437-446.

20. Reitan R, Wolfson D. The Halstead-Reitan Neuropsychological Test Battery: Theory and Clinical Interpretation. Tucson: Neuropsychology Press; 1993.

21. Heaton RK, Grant I, Matthews CG, PAR Staff. $H R B$ Comprebensive Norms Computer Program. Lutz, Florida: Par, Inc; 1991.

22. Heaton RK, Grant I, Anthony WZ, Lehman RAW. A comparison of clinical and automated interpretation of the Halstead-Reitan Battery. J Clin Neuropsychol. 1981;3:121-141.

23. Beaumont JG. The validity of the Category Test administered by on-line computer. J Clin Psychol. 1975;31:458-462.

24. Choca J, Laatsch L, Garside D, Arnemann C. Category Test Computer Program 6.0. Tonowanda, NY: MHS; 1987.

25. Choca JP, Morris J. Administering the Category Test by computer: equivalence of results. Clin Neuropsychol. 1992;6:9-15.

26. Miller DC. Computerized Version of the Category Test for the Macintosh Personal Computer. Adult Form. Denton, Texas: Author; 1993.

27. Browndyke JN. The Remote Neuropsychological Assessment Category Test: Development and Validation of a Computerized, Internet-Based Neuropsychological Assessment Measure. Doctoral Dissertation; Baton Rouge, LA: Louisiana State University; 2001.

28. Mercer WN, Harrell EH, Miller DC, Childs HW, Rockers DM. Performance of brain-injured versus healthy adults on three versions of the category test. Clin Neuropsychol. 1997;11:174-179.

29. Berg EA. A simple objective test for measuring flexibility in thinking. J Gen Psychol. 1948;39:1522. 
30. Horowitz T, Schatz P, Chute DL. Trends in neuropsychological test usage. Arch Clin Neuropsychol. 1997;12:281.

31. Keller FF, Davis HP. Card Sort. Ver 1.O. Colorado Springs, CO: Colorado Assessment Tests; 1998.

32. Heaton R. Wisconsin Card Sorting Test: Computer Version 3 for Windows ${ }^{\circledR}$. Research Edition. Lutz, Florida: Psychological Assessment Resources; 1999.

33. Fortuny LA, Heaton RK. Standard versus computerized administration of the Wisconsin Card Sorting Test. Clin Neuropsychol. 1996;10:419-424.

34. Tien AY, Spevack TV, Jones DW, Pearlson GD, Schlaepfer TE, Strauss ME. Computerized Wisconsin Card Sorting Test: comparison with manual administration. Kaobsiung J Med Sci. 1996;12:479485.

35. Feldstein SN, Keller FR, Portman RE, Durham RL, Klebe KJ, Davis HP. A comparison of the computerized and standard versions of the Wisconsin Card Sorting Test. Clin Neuropsychol. 1999;13:303313.

36. Kane RL, Kay GG. Computerized assessment in neuropsychology: a review of tests and test batteries. Neuropsychol Rev. 1992;3:1-117.

37. American Psychological Association. Guidelines for Computer-Based Tests and Interpretations. Washington, DC: American Psychological Association; 1986.

38. Campbell KA, Rohlman DS, Storzbach D, et al. Testretest reliability of psychological and neurobehavioral tests self-administered by computer. Assess ment. 1999;6:21-32.

39. Kane RL, Reeves DL. Computerized test batteries. In: Horton AM, Wedding D, Webster J, eds. The Neuropsychology Handbook: Vol. 1. Foundations and Assessment, 2nd ed. New York: Springer Publishing Co.; 1997:423-467.

40. Mead AD, Drasgow F. Equivalence of computerized and paper-and-pencil cognitive ability tests: a metaanalysis. Psychol Bull. 1993;114:449-458.

41. Barak A. Psychological applications on the Internet: a discipline on the threshold of a new millennium. Appl Prevent Psychol. 1999;8:231-245.

42. Space LG. The computer as psychometrician. Behav Res Meth Instr. 1981;13:595-606.

43. Honaker L. The equivalency of computerized and conventional MMPI administration: a critical review. Clin Psychol Rev. 1988;8:561-577.

44. Bennett RE. Using new technology to improve assessments. Educ Measurement. 1999;Fall:5-12.

45. Rosen LD, Sears DC, Weil MM. Measuring Technopbobia. A manual for the administration and scoring of three instruments: Computer Anxi- ety Rating Scale (Form C), General Attitudes Toward Computers Scale (Form C) and Computer Thoughts Survey (Form C). [Computerphobia Reduction Program]. Dominguez Hills, CA: California State University; 1992.

46. Burke MJ, Normand J. Computerized psychological testing: overview and critique. Prof Psychol-Res Pr. 1987;18:42-51.

47. Reed AV. Microcomputer display timing: problems and solutions. Behav Res Meth Instr Comp. 1979;11:572-576.

48. Westall R, Perkey MN, Chute DL. Millisecond timing on Apple's Macintosh revisited. Behav Res Meth Instr Comp. 1989;21:540-547.

49. Cohen J, MacWhinney B, Flatt M, Provist J. PsyScope: an interactive graphic system for designing and controlling experiments in the psychology laboratory using Macintosh computers. Behav Res Meth Instr Comp. 1993;25:257-271.

50. Chute DL, Westall RF. PowerLaboratory. Pacific Grove, CA: Brooks/Cole; 1996.

51. Jarvis B. MediaLab, DirectRT. New York: Empirisoft Research Software; 2002.

52. Gur RC, Alsop D, Glahn D, et al. A fMRI study of gender differences in regional activation to a verbal and a spatial task. Brain Lang. 2000;74:157-170.

53. Gur RC, Ragland JD, Moberg PJ, et al. Computerized neurocognitive scanning: I. Methodology and validation in healthy people. Neuropsychopharmacology. 2001;25:766-776.

54. Collins $M$. New developments in the management of sports-related concussions. Presentation at the 21st Annual Conference of the National Academy of Neuropsychology. San Francisco, CA. November, 2001.

55. Echemendia RJ, Julian LJ. Mild traumatic brain injury in sports: neuropscyhology's contribution to a developing field. Neuropsychol Rev. 2001;11:69-88.

56. Barth JT, Alves WM, Ryan TV, et al. Head injury in sports: neuropsychological sequelae and recovery of function. In: Levin HS, Eisenberg HM, Benton AL, eds. Mild Head Injury. New York: Oxford Press; 1989.

57. Collins MW, Grindel SH, Lovell MR, et al. Relationship between concussion and neuropsychological performance in college football players. JAMA. 1999;282:964-970.

58. Lovell MR, Collins MW. Neuropsychological assessment of the college football player. J Head Trauma Rebabil. 1998;13:9-26.

59. Moser RS, Schatz P. Enduring effects of concussion in youth athletes. Arch Clin Neuropsychol. 2002;17:81-90. 
60. Brooks J. Epidemiology and Prevention in Youth Sports. Lincoln: NE: Brain Injury Association of Nebraska; 1998.

61. Echemendia RJ, Putukian M, Mackin RS, Julian L, Shoss N. Neuropsychological test performance prior to and following sports-related mild traumatic brain injury. Clin J Sport Med. 2001;11:23-31.

62. Collins MW, Lovell MR, Mckeag DB. Current issues in managing sports-related concussion. JAMA. 1999;282:2283-2285.

63. Schatz P, MacNamara K. Enduring effects of previous concussion in college freshmen and sophomores. Arch Clin Neuropsychol. 2001;16:746.

64. CogSport. Parkville, Victoria, Australia: CogState, Ltd.; 1999.

65. Makdissi M, Collie A, Maruff P, et al. Computerised cognitive assessment of concussed Australian Rules footballers. BrJ Sports Med. 2001;35:354-360.

66. Collie A, Darby D, Maruff P. Computerised cognitive assessment of athletes with sports related head injury. Br J Sports Med. 2001;35:297-302.

67. Erlanger DM, Feldman DJ, Kutner K. Concussion Resolution Index ${ }^{\odot}$. New York: HeadMinder, Inc.; 1999.

68. Erlanger DM, Feldman D, Kutner K, et al. Development and validation of a web-based neuropsychological test protocol for sports-related return-toplay decision making. Arch Clin Neuropsychol. in press.

69. Erlanger D, Saliba E, Barth J, Almquist J, Webright W, Freeman J. Monitoring resolution of postconcussion symptoms in athletes: preliminary results of a webbased neuropsychological protocol. J Athl Train. 2001;36:280-287.

70. McCrae M, Kelly JP, Randolph C. The Standardized Assessment of Concussion (SAC): Manual for Administration, Scoring and Interpretation. Washington, DC: Brain Injury Association; 1997.

71. Lovell MR, Collins MW, Podell K, Powell J, Maroon J. ImPACT: Immediate Post-Concussion Assessment and Cognitive Testing. Pittsburgh, PA: NeuroHealth Systems, LLC; 2000.

72. Maroon JC, Lovell MR, Norwig J, Podell K, Powell JW, Hartl R. Cerebral concussion in athletes: evaluation and neuropsychological testing. Neurosurg. 2000;47:659-669; discussion 669-672.

73. Iverson GL, Franzen MD. Using multiple objective memory procedures to detect simulated malingering. J Clin Exp Neuropsychol. 1996;18:38-51.

74. Gutierrez JM, Gur RC. Detection of malingering using forced-choice techniques. In: Reynolds CR, ed. Detection of Malingering during Head Injury Litigation. New York: Plenum Press; 1998:81-104.
75. Pankratz L. A new technique for the assessment and modification of feigned memory deficit. Percept Mot Skills. 1983;57:367-372.

76. Etcoff LM, Kampfer KM. Practical guidelines in the use of symptom validity and other psychological tests to measure malingering and symptom exaggeration in traumatic brain injury cases. Neuropsychol Rev. 1996;6:171-201.

77. Hiscock M, Hiscock CK. Refining the forced-choice method for the detection of malingering. J Clin Exp Neuropsychol. 1989;11:967-974.

78. Bianchini KJ, Mathias CW, Greve KW. Symptom validity testing: a critical review. Clin Neuropsychol. 2001;15:19-45.

79. Slick DJ, Hoop G, Strauss D. The Victoria Symptom Validity Test. Odessa, FL: Psychological Assessment Resources; 1995.

80. Allen LM, Condor RL, Green P, Cox DR. CARB Manual for the Computerized Assessment of Response Bias. Durham, NC: Cognisyst, Inc.; 1997.

81. Green P, Allen LM III, Astner K. Word Memory Test ${ }^{\mathrm{TM}}(W M T)$. Durham, NC: CogniSyst, Inc.; 2000.

82. Slick DJ, Hopp G, Strauss E, Spellacy FJ. Victoria Symptom Validity Test: efficiency for detecting feigned memory impairment and relationship to neuropsychological tests and MMPI-2 validity scales. J Clin Exp Neuropsychol. 1996;18:911922.

83. Grote CL, Kooker EK, Garron DC, Nyenhuis DL, Smith CA, Mattingly ML. Performance of compensation seeking and non-compensation seeking samples on the Victoria symptom validity test: crossvalidation and extension of a standardization study. J Clin Exp Neuropsychol. 2000;22:709-719.

84. Strauss E, Hultsch DF, Hunter M, Slick DJ, Patry $\mathrm{B}$, Levy-Bencheton $\mathrm{J}$. Using intraindividual variability to detect malingering in cognitive performance. Clin Neuropsychol. 1999;13:420-432.

85. Slick DJ, Iverson GL, Green P. California Verbal Learning Test indicators of suboptimal performance in a sample of head-injury litigants. J Clin Exp Neuropsychol. 2000;22:569-579.

86. Green P, Iverson GL, Allen L. Detecting malingering in head injury litigation with the Word Memory Test. Brain Inj. 1999;13:813-819.

87. Iverson GL. Can malingering be identified with the judgment of line orientation test? Appl Neuropsychol. 2001;8:167-173.

88. Schatz P, Moelter S, Fragnito M. Computer-based assessment of malingering: response requirement effects [abstract]. Arch Clin Neuropsychol. 1999; $14: 747$. 
89. Ball C, Puffett A. The assessment of cognitive function in the elderly using videoconferencing. $J$ Telemed Telecare. 1998;4(Suppl 1):36-38.

90. Ball C, Tyrrell J, Long C. Scoring written material from the Mini-Mental State Examination: a comparison of face-to-face, fax and video-linked scoring. $J$ Telemed Telecare. 1999;5:253-256.

91. Ball CJ, Scott N, McLaren PM, Watson JP. Preliminary evaluation of a Low-Cost VideoConferencing (LCVC) system for remote cognitive testing of adult psychiatric patients. Br J Clin Psychol. 1993;32(Pt 3):303-307.

92. Harvey R, Roques PK, Fox NC, Rossor MN CANDID-Counseling and Diagnosis in Dementia: a national telemedicine service supporting the care of younger patients with dementia. Int J Geriatr Psychiatry. 1998;13:381-388.

93. Lee JH, Kim JH, Jhoo JH, et al. A telemedicine system as a care modality for dementia patients in Korea. Alzbeimer Dis Assoc Disord. 2000;14:94101.

94. Montani C, Billaud N, Tyrrell J, et al. Psychological impact of a remote psychometric consultation with hospitalized elderly people. J Telemed Telecare. 1997;3:140-145.

95. Nesselroade JR, Pedersen NL, McClearn GE, Plomin $\mathrm{R}$, Bergeman CS. Factorial and criterion validities of telephone-assessed cognitive ability measures. Age and gender comparisons in adult twins. Res Aging. 1988;10:220-234.

96. Williams JM, Browndyke JN. Neuropsychology on the Internet. Presentation at the 16th Annual Meeting of the National Academy of Neuropsychology. New Orleans, LA, October/November 1996.

97. Monteiro IM, Boksay I, Auer SR, Torossian C, Sinaiko E, Reisberg B. Reliability of routine clinical instruments for the assessment of Alzheimer's disease administered by telephone. J Geriatr Psychiatry Neurol. 1998;11:18-24.

98. Ball C, McLaren P. The tele-assessment of cognitive state: a review.J Telemed Telecare. 1997;3:126-131.

99. Risser AH. e-Practice: Internet resources for the practicing neuropsychologist. In: Lamberty G, ed. The Practice of Clinical Neuropsychology. Amsterdam: Swets Publishing; in press.

100. Meier ST. Predicting individual differences in perfor- mance on computer-administered tests and tasks: development of the computer aversion scale. Comput Hum Behav. 1988;4:175-187.

101. Browndyke JN, Gouvier WD, Waters WF. Predictors of ANS sympathetic activity and intensity in a large-scale MHI population: Online Neuropsychology Project II. Arch Clin Neuropsychol. 1999;14:26.

102. Browndyke JN, Santa Maria MP, Pinkston JB, Gouvier WD. Online neuropsychology project: a survey of general head injury and prevention knowledge between professionals and non-professionals. Arch Clin Neuropsychol. 1998;13:133.

103. Brain.com/Hot Brain, Inc. Products and Info for More Brain Power. Accessed February, 2002. Available at: http://www.brain.com.

104. Marshall WW, Haley RW. Use of a secure Internet Web site for collaborative medical research. JAMA. 2000;284:1843-1849.

105. Coffin RJ. Motivational influences on computerrelated affective states. Comp Hum Behav. 1999; 15:549-569.

106. Feldman DJ, Erlanger D, Kroger H. The effect of computer familiarity on computerized tests. J Int Neuropsychol Soc. 2001;7:133

107. Johnson DF, White CB. Effects of training on computerized test performance in the elderly. $J A p p l$ Psychol. 1980;65:357-358.

108. Shneiderman B. Designing the User Interface: Strategies for Effective Human Computer Interaction, 3rd ed. New York: McGraw-Hill; 1998.

109. American Psychological Association Committee on Professional Standards \& Committee on Psychological Tests and Assessment. Division 40. Task force report in computer-assisted neuropsychological evaluation. Clin Neuropsychol. 1987;2:161-184.

110. Matthews CG, Harley JP, Malec J. Guidelines for computer-assisted neuropsychological rehabilitation and cognitive remediation. Clin Neuropsychol. 1991;5:3-19.

111. Schultheis MT, Chute DL. Development of an ecologically valid, computerized, driving assessment program: The Neurocognitive Driving Test. Arch Clin Neuropsychol. 1999;14(8):794-795.

112. Schultheis MT, Rizzo AA. The application of virtual reality technology for rehabilitation. Rehab Psychol. 2001;46:296-311. 